\title{
65. Ueber die periodische Erneuerung der Köpfe der Kolonie bei gewissen Synascidien.
}

\author{
Von Asajiro OKA, M.I.A. \\ Tokyo. \\ (Comm. May 12, 1933.)
}

Es ist wohl bekannt, dass bei koloniebildenden Ascidien die Lebensdauer der Einzeltiere im Vergleich mit der der gesamten Kolonie sehr kurz ist. Indessen tritt diese Tatsache gewöhnlich nicht deutlich hervor, weil die alten Zooide in der Regel einzeln durch die neuen ersetzt werden, ohne dass der ganze Habitus der Kolonie dadurch irgendwie beeinträchtigt wird. Sie fällt erst dann auf, wenn die Einzeltiere gruppenweise und zusammenhängend erneuert werden, wie im unten mitgeteilten Fall.

Beim Studium der Kolonien von Sigillinaria clavata aus Kamttchaka fielen mir einige Köpfe dadurch aus, dass sie sich ausserordentlich leicht vom Stiel abtrennen liessen. Als ich einen solchen mit dem Messer längsweise aufzuschneiden versuchte, löste sich dieser, ich möchte sagen, beinahe von sich selbst los. An seiner Stelle blieb ein kleiner aber ganz regelmässig gestalteter neuer Kopf zurück, der bis dahin innerhalb des alten, gleichsam in einer Kapsel, versteckt war. Im neuen Kopf fanden sich ziemlich dicht gedrängt eine Anzahl reifer Knospen, die offenbar bereit waren, die abgeworfenen alten Zooide sogleich zu ersetzen.

Der abgetrennte alte Kopf hat an seiner Basis, wo er mit dem Stiel verbunden war, eine tiefe Aushöhlung, deren Grösse und Gestalt denen des neuen Kopfes genau entsprechen. Die Innenfläche der Höhle ist vollkommen glatt, sodass man annehmen darf, dass sich der alte und neue Kopf an dieser Stelle bereits voneinander abgetrennt hatten und nur an der Peripherie hängen blieben. Was den alten Kopf besonders auszeichnet, ist die aussergewöhnlich zarte Beschaffenheit der Testa, die hier sehr weich gallertartig, farblos und ganz durchsichtig ist.

Der neue Kopf ist von abgerundet kegelförmiger Gestalt, nur ein wenig höher als breit, und an der Basis ebenso dick wie der ihn tragende Stiel. Die Testa ist sehr fest, knorpelig, halb durchscheinend und blass rötlich gefärbt. Die Oberfläche ist vollkommen glatt. Die in die Testa eingebetteten reifen Knospen sind 5-6 mm lang, 1-1.2 mm dick und ähneln gewissermassen verkleinerten Bananen in Gestalt. Sie 
sind von hell bräunlicher Farbe und ganz undurchsichtig, sodass es nötig ist, sie in Schnitten zu zerlegen, um die innere Struktur zu untersuchen.

Die reife Knospe zeigt, abgesehen von der Grösse, eine bemerkenswerte Aehnlichkeit mit dem Einzeltier von Aphanibranchion japonicum, ${ }^{1)}$ einer Form, die ich bereits im Jahre 1906 bekannt gemacht habe. Schon in der äusseren Körperform stimmen beide gut überein, indem sie verlängert eiförmig mit stumpf zugespitzten Enden sind.

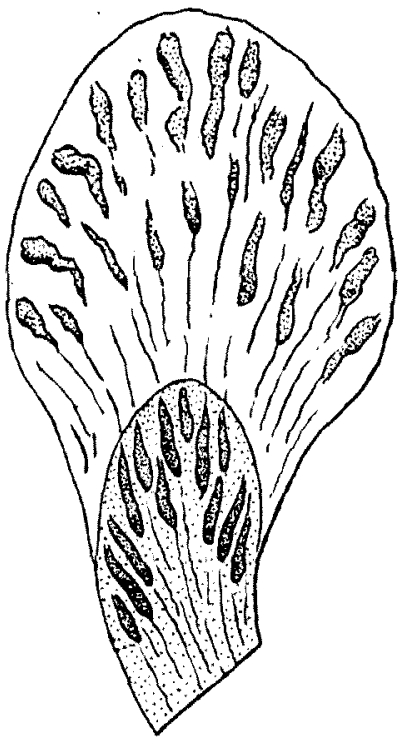

A

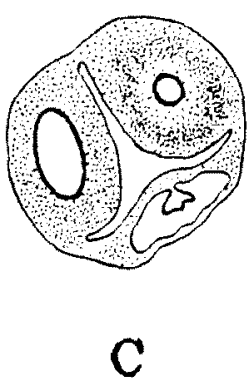

$B$

Sigillinaria clavata

A Längsschnitt eines Kopfes. Nat. Gr.

B Reife Knospe, als durchsichtig gedacht. $\times 8$.

C Querschnitt derselben. $\times 16$.

Beide sind auch vollkommen opak, infolge der Anwesenheit von zahlreichen Zellen mit körnigem Inhalt. Betreffs der inneren Organisation weisen beide Formen so völlige Uebereinstimmung auf, dass man unbedingt ihre nahe Verwandtschaft anerkennen muss. Die Knospe enthält nämlich einen einfachen Darmkanal und ein geräumiges Perikard mit schlauchförmigem Herz, die genau nach dem Typus von Aphanibranchion gebaut sind. Auch ein Leibeshöhle vortäuschender Epikardialschlauch ist vorhanden, nur die Geschlechtsorgane sind noch nicht ausgebildet. Es fehlt aber der Thorax noch vollständig.

1) Oka, A.: Aphanibranchion, eine neue Synascidiengattung aus Japan. Annot. Zool. Japon., Vol. V (1906). 
Um ein erwachsenes Einzeltier zu werden, bedarf die Knospe noch folgender Umbildungen. Zunächst entwickelt sich am vorderen Ende ein neuer Thorax mit dem zuerst ganz rudimentären Kiemensack. Gleichzeitig mit dem Wachstum desselben bildet sich an der Oberfläche des Kopfes eine zuerst sehr dünne, später aber allmählich dicker werdende Schicht von weicher, gallertartiger Testamasse. Auf diese Weise wird ein Stadium erreicht, in welchem ein jedes Einzeltier einen von weicher Testamasse umhüllten Thorax und ein noch in die festere Testapartie eingebettetes Abdomen besitzt. Schliesslich verlässt auch das Abdomen den letzteren Testaabschnitt, um in die nunmehr genügend dick gewordene Zone der weichen Testamasse einzutreten. Derartiger Umbildungsvorgang bringt es mit sich, dass der Uebergang von weicher zu fester Testapartie immer ganz plötzlich ist.

Ich benutze die Gelegenheit, beiläufig die Resultate meiner erneuten Untersuchungen über die Gattung Aphanibranchion kurz mitzuteilen. Ein vergleichendes Studium zahlreicher Kolonien von dieser Gattung und von Syndiazona ${ }^{1)}$ führte mich zu der Ueberzeugung, dass erstere nichts anderes darstellt als ein Regenerationsstadium von diesem letzteren. Auch bei Syndiazona scheint eine periodische Erneuerung der oberflächlichen Zone der Testamasse samt den darin enthaltenen Körperabschnitten der Einzeltiere stattzufinden, wodurch die Kolonie eine Weile ein ganz anderes Aussehen erhält.

1) Oka, A.: On a New Genus of Compound Ascidians (Syndiazona nov. gen.), Proc. 2 (1926). 